ISSN 0103-5150

Fisioter. Mov., Curitiba, v. 27, n. 4, p. 495-503, out./dez. 2014

Licenciado sob uma Licença Creative Commons

DOI: http://dx.doi.org.10.1590/0103-5150.027.004.A001

\title{
The effects of different TENS frequencies applied to LU7 acupoint on cold-induced pain test
}

\author{
Ação de variadas frequências de TENS aplicadas no \\ acuponto P7 na dor induzida pela hipotermia
}

\section{Andressa Lais Salvador de Melo ${ }^{[a]}$, Erika Liliana Cruz Gomes ${ }^{[b]}$, Vanessa Oliveira Ximenes ${ }^{[c]}$, Eduardo José Nepomuceno Montenegro ${ }^{[d]}$}

[a] Physical Therapy undergraduate student at Universidade Federal de Pernambuco (UFPE), Recife, PE - Brazil, e-mail: andressa.melo.fisio@gmail.com

[b] Physical Therapy undergraduate student at Universidade Federal de Pernambuco (UFPE), Recife, PE - Brazil, e-mail: erikalcgomes@gmail.com

[c] Physical Therapy undergraduate student at Universidade Federal de Pernambuco (UFPE), Recife, PE - Brazil, e-mail: vanessa-pitanga@hotmail.com

[d] PhD, professor at Universidade Federal de Pernambuco, Departamento de Fisioterapia, Recife, PE - Brazil, e-mail: eduardo3montenegro@gmail.com

\section{Abstract}

Introduction: Pain represents a frequent phenomenon among the general population with great socioeconomic impact. TENS is one of the most common forms of electroanalgesia. However, totally effective stimulation parameters remain uncertain. Thus, this study aims to assess the effects of $4 \mathrm{~Hz}, 10 \mathrm{~Hz}$ and $100 \mathrm{~Hz}$ TENS applied to the LU7 (Lieque) acupoint on cold-induced pain in young healthy subjects. Methods: 100 volunteers, divided into five groups (three TENS groups, one electrode group and one placebo group), completed six experimental cycles. Each cycle comprised three phases: pretreatment, treatment and posttreatment. In each cycle, pain was induced by immersion of the hand into ice water and the pain threshold latency was measured. For the analysis of results, we used the one-way ANOVA test, followed by the StudentNewman-Keuls post hoc test. The level of significance was $\mathrm{p}<0.05$. Results: The $4 \mathrm{~Hz}$ TENS group the pain showed elevation of the pain threshold during the treatment phase, when compared to pretreatment $(\mathrm{p}<$ 0.05). This elevation was maintained in the post-treatment phase. The other groups showed no changes 
in the pain threshold. Conclusion: $4 \mathrm{~Hz}$ TENS applied with $1 \times 1 \mathrm{~cm}$ electrodes to LU7 acupoint increases hypothermia-induced pain threshold latency in young healthy subjects.

Keywords: Transcutaneous Electrical Nerve Stimulation. Acupuncture points. Hypothermia. Pain.

\section{Resumo}

Introdução: A dor é um fenômeno frequente na população e pode gerar grande impacto socioeconômico. A TENS é um dos meios mais comuns de eletroanalgesia, mas parâmetros de estimulação totalmente eficazes permanecem incertos. Neste cenário, o presente estudo objetiva verificar a influência da TENS de 4, 10 e $100 \mathrm{~Hz}$ na dor induzida pela hipotermia quando aplicada no acuponto P7 (Lieque) em sujeitos jovens saudáveis. Metodologia: Cem voluntários distribuídos em cinco grupos (três TENS, um apenas com Eletrodo e um Placebo) passaram por seis ciclos experimentais divididos em três etapas (Pré-tratamento, Tratamento e Pós-tratamento), em cada ciclo houve indução de dor pela imersão da mão do sujeito em água gelada, onde foi medida a variável da latência do limiar da dor. Utilizou-se o Teste de ANOVA de um critério seguido do Teste post hoc de Student-Newman-Keuls para análise dos resultados. $O$ nível de significância adotado foi $p<0,05$. Resultados: O grupo TENS de $4 \mathrm{~Hz}$ obteve aumento do limiar de dor durante o tratamento quando comparado com o pré-tratamento $(p<0,05)$ e no pós-tratamento este aumento foi mantido. Os outros grupos não apresentaram alterações na latência do limiar da dor. Conclusão: A TENS de $4 \mathrm{~Hz}$ aplicada com eletrodos de $1 \mathrm{~cm}^{2}$ no acuponto P7 aumenta a latência do limiar de dor induzida pela hipotermia em sujeitos jovens saudáveis.

Palavras-chave: Estimulação Elétrica Nervosa Transcutânea. Pontos de acupuntura. Hipotermia. Dor.

\section{Introduction}

According to the International Association for the Study of Pain, "pain is an unpleasant sensory and emotional experience associated with actual or potential tissue damage" (1). It is present in over 70\% of patients who seek medical care for various reasons in Brazil (2). Langley et al. (3), in their study with a sample of Spanish subjects, found a strong association between the symptom of pain and the reduction in the workforce, absenteeism and presenteeism, demonstrating the great socio-economic impact of this phenomenon.

Several techniques can be used to reduce pain symptoms and provide comfort to the patient (4). Among them, we highlight the stimuli of acupuncture points (acupoints). In the traditional way, these stimuli are produced through percutaneous needles. However, there are some undesirable side effects or problems, such as the phobia of some patients for needles; tissue trauma (minor bleeding and bruising); needle breakage; and contamination resulting from poor cleaning practices (for example, hepatitis B and staphylococci) $(5,6,7,8,9)$.
Several non-invasive therapeutic alternatives for the stimulation of acupoints are being explored, such as local pressure (acupressure), laser radiation, infrared radiation, magnetic fields, electric currents, among others $(10,11,12,13,14)$. Transcutaneous electrical nerve stimulation (TENS) is one of these alternatives (14). The term Acu-TENS has been currently used to describe the application of TENS to acupoints and the term TEAS (transcutaneous electrical stimulation at acupoints) indicates any transcutaneous electrical stimulation at acupoints. Thus, an Acu-TENS is a TEAS $(15,16)$. In this study, the definitions used for the experimental groups refer specifically to the stimulation frequencies and not to pre-established terms found in the literature.

Despite the fact that the amount of knowledge about this treatment modality has increased and it is considered an important form of clinical electroanalgesia, its analgesic mechanism is not yet fully understood $(17,18)$.

The findings of previous studies indicate that these therapeutic resources activate the spinal afferent pathways according to the gate-control theory of pain by Melzack and Wall (19), in which the gray 
matter of the spinal dorsal horn modulates sensory afferent traffic. Moreover, the produced antinociception is associated with supraspinal mechanisms through the activation of opioidergic, adrenergic, cholinergic and serotonergic receptors in the Central Nervous System (CNS) $(20,21,22)$.

The clinical and scientific interest in these techniques has greatly increased in the last decade. Pain management is the most studied and best documented condition for treatment with transcutaneous electrical stimulation. Nevertheless, further clinical and basic studies are needed to better define the optimal conditions for these electrical stimulations. Researches have been conducted both through clinical trials and experimental pain models in healthy subjects, using different noxious stimuli, such as pressure, hyperthermia and hypothermia. These stimuli are used to provoke pain sensation and make it possible to control variables such as intensity and duration of pain $(23,24,25,26)$.

Thus, this study aimed to assess the effects of $4 \mathrm{~Hz}, 10 \mathrm{~Hz}$ and $100 \mathrm{~Hz}$ TENS and electrodes applied to the LU7 acupoint (Lieque) on acute cold-induced pain threshold and check the effect of the placebo stimulus.

\section{Methods}

Design

The study employed a quasi-experimental, nonrandomized, single-blind design.

Place of study development

All experimental procedures were performed from November 2001 to July 2012 at the Laboratory of Electrothermal and Phototerapy, Department of Physical Therapy, Federal University of Pernambuco (UFPE).

\section{Subjects}

The study included 100 subjects ( 49 men and 51 women), who were recruited through verbal invitation. Inclusion criteria were: age between 18 and 30 years; absence of any pathological condition; not being pregnant; not experiencing menstrual bleeding or premenstrual tension at the time of the study; and not making use of any allopathic, homeopathic and/ or other drugs that may interfere with the pain process. Exclusion criteria were: disturbances of surface and deep sensitivity in the body region subjected to hypothermia and/or in the area of electrode placement; hypersensitivity to cold; discomfort during the application of electrical current; and having previous knowledge about the effects of TENS and acupoints. All subjects signed an informed consent form. This project was approved by the Ethics Committee on Research with Humans Subjects of the Center for Health Sciences, Federal University of Pernambuco, under protocol number CAAE 0106.0.172.000-11.

In order to avoid influencing subjects' behaviors, they did not receive prior knowledge about the existence of the experimental groups. This information was only provided at the end of all phases of the research. All experimental procedures were carried out at different times for each experimental group. They were divided by convenience sampling (order of arrival of the volunteers) into in five groups: 1) $100 \mathrm{~Hz}$ TENS Group ( $\mathrm{n}=20,9$ men, 11 women); 2) $10 \mathrm{~Hz}$ TENS Group ( $\mathrm{n}=20,10$ men, 10 women); 3) $4 \mathrm{~Hz}$ TENS Group ( $\mathrm{n}=20,10$ men, 10 women); 4) Placebo Group ( $\mathrm{n}=20,13$ men, 7 women); and 5) Electrode Group ( $\mathrm{n}=20,7$ men, 13 women).

\section{Preparation for data collection}

The volunteers who met the inclusion criteria were asked to go to the lab and sit down on a chair. Next, the area where the electrodes would be placed was cleaned with cotton wool soaked in $70 \%$ ethyl alcohol. Then two $1 \times 1 \mathrm{~cm}$ carbon-silicon electrodes were fixed to the upper limb ipsilateral, according to the group into which the subject was allocated in the study, using adhesive plaster and coupling gel. (A) for the TENS Groups and the Electrode Group, one electrode was placed at the LU7 (Lieque) acupoint, located on the radial aspect of the forearm, 1.5 cun above the transverse crease of the wrist. In clinical practice, this acupoint is stimulated in order to relief the pain caused by arthritis and tenosynovitis of the wrist (27). The second electrode was placed immediately proximal to the first, on the path of the lung meridian, which belongs to the studied acupoint; (B) for the Placebo Group, the first electrode was placed at the midpoint of the lateral 
border of the acromion of the scapula and the second electrode was placed immediately distal to the first. In all volunteers, the electrodes were placed in such a way as to maintain their whole surface in contact with the skin, without any additional pressure, during the entire time of the experiment ( 1 hour). Two containers, one containing warm water $\left(37^{\circ} \mathrm{C}\right)$ and another containing ice water $\left(0-2{ }^{\circ} \mathrm{C}\right)$, were positioned next to the volunteer, who received detailed instructions on how to proceed throughout the entire experiment.

\section{Cold Induction Pain Test}

All subjects underwent six experimental cycles of 10 minutes. Each cycle comprised three phases (pretreatment, treatment and post-treatment) (Figure 1). At each cycle (Figure 2), the subject was subjected to pain in the ipsilateral hand, caused by cold induced-pain.
First, the subject was asked to immerse his/her hand up to the wrist crease in the warm water $\left(37^{\circ} \mathrm{C}\right)$ container. The water had been heated by using an electric boiler. After five minutes, the subject was asked to remove his/her hand from this container and placed it in the cold water $\left(0-2{ }^{\circ} \mathrm{C}\right)$ container. Temperature control was achieved using an INCOTERM-L 212/04 mercury thermometer. Subjects were instructed to report when they started to feel pain. The time difference between the immersion of the hand in ice water and this moment of pain sensation and withdrawal of the hand from the water was interpreted as the pain threshold (digital stopwatch CRONOBIO SW2018). After a rest interval, during which the subjects kept their hands out of the water and which corresponded to the time required to complete the 10 -minute cycle, this procedure was repeated six times. Group differentiation occurred in the treatment phase $\left(3^{\text {rd }}\right.$ and $4^{\text {th }}$ cycles). This will be further explained next.

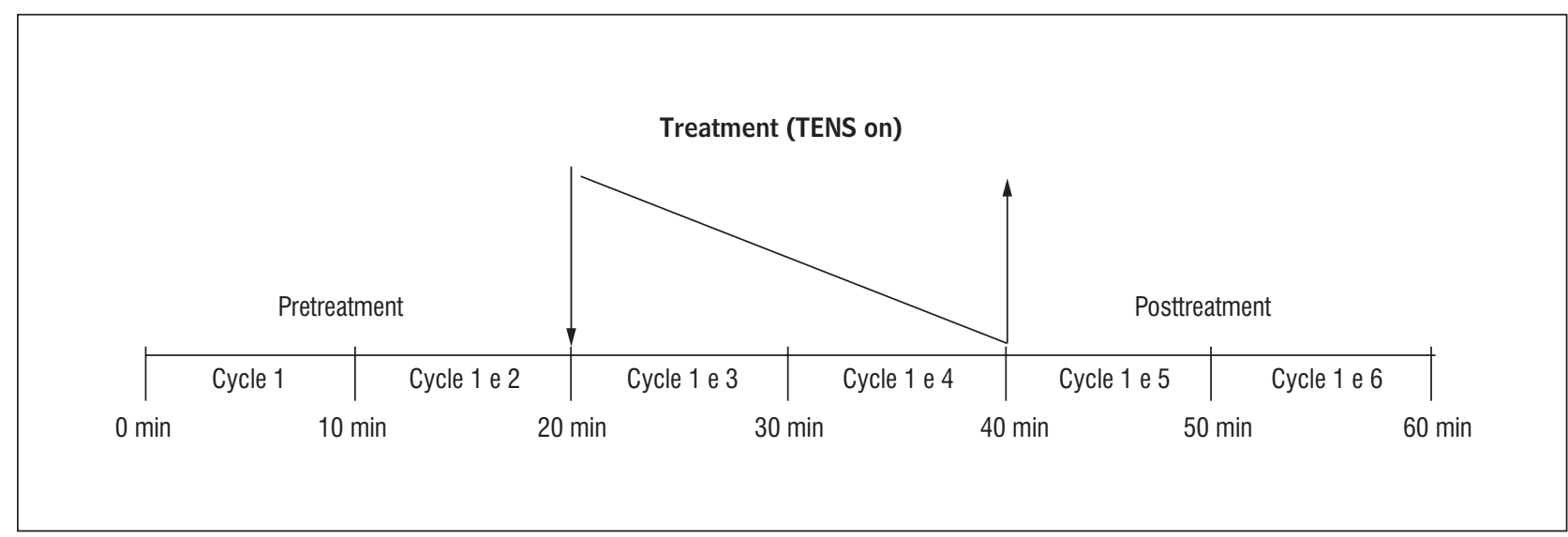

Figure 1 - Scheme showing three experimental stages

Source: Johnson and Tabasam (28).

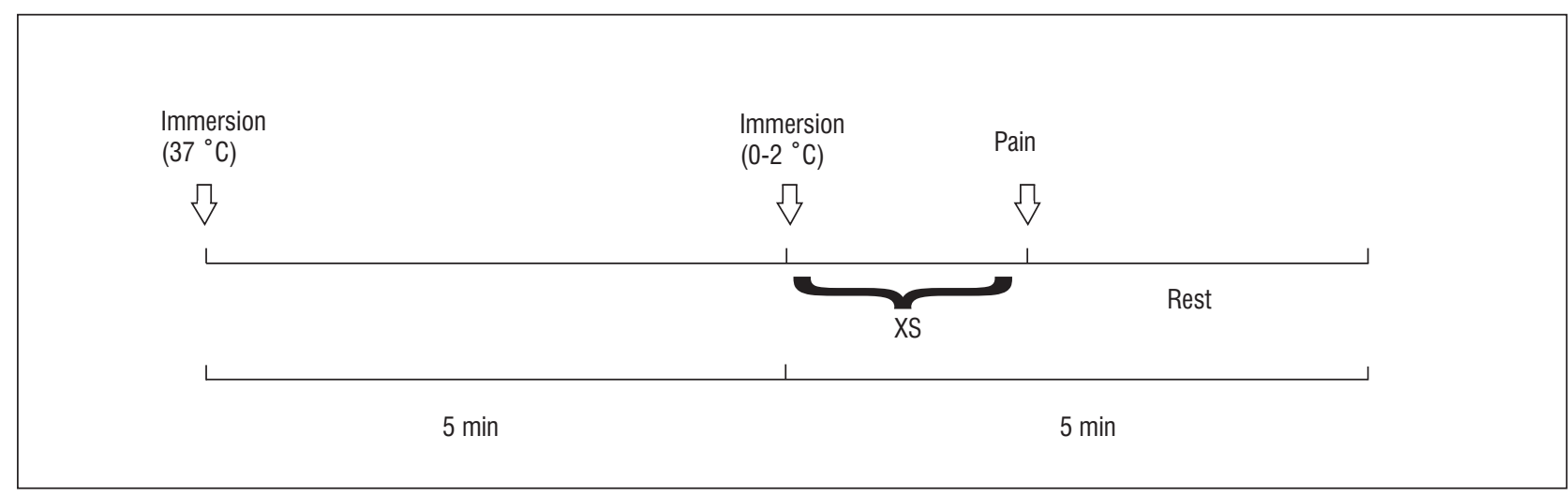

Figure 2 - Detailing of each experimental cycle

Source: Johnson and Tabasam (28). 
TENS groups

During the treatment phase, the subjects of these groups received low-frequency ( $4 \mathrm{~Hz}$ and $10 \mathrm{~Hz}$ ) TENS and high-frequency $(100 \mathrm{~Hz})$ TENS, with balanced asymmetrical biphasic waveform (delivered by a FESVIL four QUARK 995). Pulse duration was $100 \mu$ s (microseconds) and it was applied by $1 \times 1 \mathrm{~cm}$ electrodes to the LU7 acupoint (lung meridian). For the groups receiving low-frequency TENS, the intensity of the electrical current was raised to the maximum level of tolerance of the subject. For the group receiving high-frequency TENS, the intensity of the electrical current was basically sensory. Each volunteer received 20 minutes of application. At this moment, which corresponds to the two intermediate cycles, the immediate effects of TENS were evaluated. In the remaining 20 minutes, which corresponded to the two cycles of the post-treatment phase, the equipment remained turned off, in order to measure the late effects of the application.

\section{Placebo group}

Subjects in this group were also subjected to the three phases mentioned above. However, they were not treated with TENS. Instead, they were led to believe that they were being treated with an "analgesic microcurrent, which works with the very low intensity and therefore causes no sensation", in addition to having immediate and prolonged effects. As already mentioned, the electrodes were placed on the shoulder joint, where there are no acupoints or reflex points acting as such. Subjects were connected to a channel. However, a different channel was connected to the equipment (FESVIL four QUARK 995). Thus, the lights in the display were turned on, making the subjects think that they were really being electrically stimulated.

\section{Electrode group}

For this groups, just like in the TENS groups, one $1 \mathrm{x} 1 \mathrm{~cm}$ electrode was placed at the LU7 acupoint and a second electrode was placed immediately proximal to the first, on the path of the lung meridian proximal. They also went through the same experimental procedures, without any changes until the end, i.e., all cycles were the same, there was no one actual treatment phase. Our intention with this group was to eliminate the confounding variable "pressure", leaving no doubt whether the causative factor of the outcome was the electric current or the mechanical stimuli caused by the electrode that was fixed on the point. This group differed from the placebo group in the lack of verbal stimulation and of the equipment coupled to the electrodes, which were present in the placebo group.

\section{Statistical analysis}

We calculated the means of the cycles composing each phase. Thus, the six values became only three: one for each phase. Pain threshold data were presented as mean \pm standard deviation of the mean. In order to compare the phases of each group (TENS groups, Placebo group and Electrode group) regarding the pain threshold, we used the one-way ANOVA test, followed, when necessary, by the Student-Newman-Keuls post hoc test. The level of significance was $\mathrm{p}<0.05$.

\section{Results}

Figure 3 shows the pain threshold results in the TENS groups, in the Placebo group and in the Electrode group, respectively, in all three experimental phases.

\section{Discussion}

Acute pain was induced by cold. We used a simple model of cold induced pain test, which involves no risk and in which the pain ceases immediately after removal of the stimulus (28). In this model, the low temperature leads to a painful sensation, both through vasoconstriction and the activation of thermal nociceptors, which signal potential tissue damage and send this information through peripheral and central pathways to the somatosensory cortex (29).

In this study, we analyzed one component of pain: the sensory component. It describes how the painful message (nociception) reaches the central nervous system. 


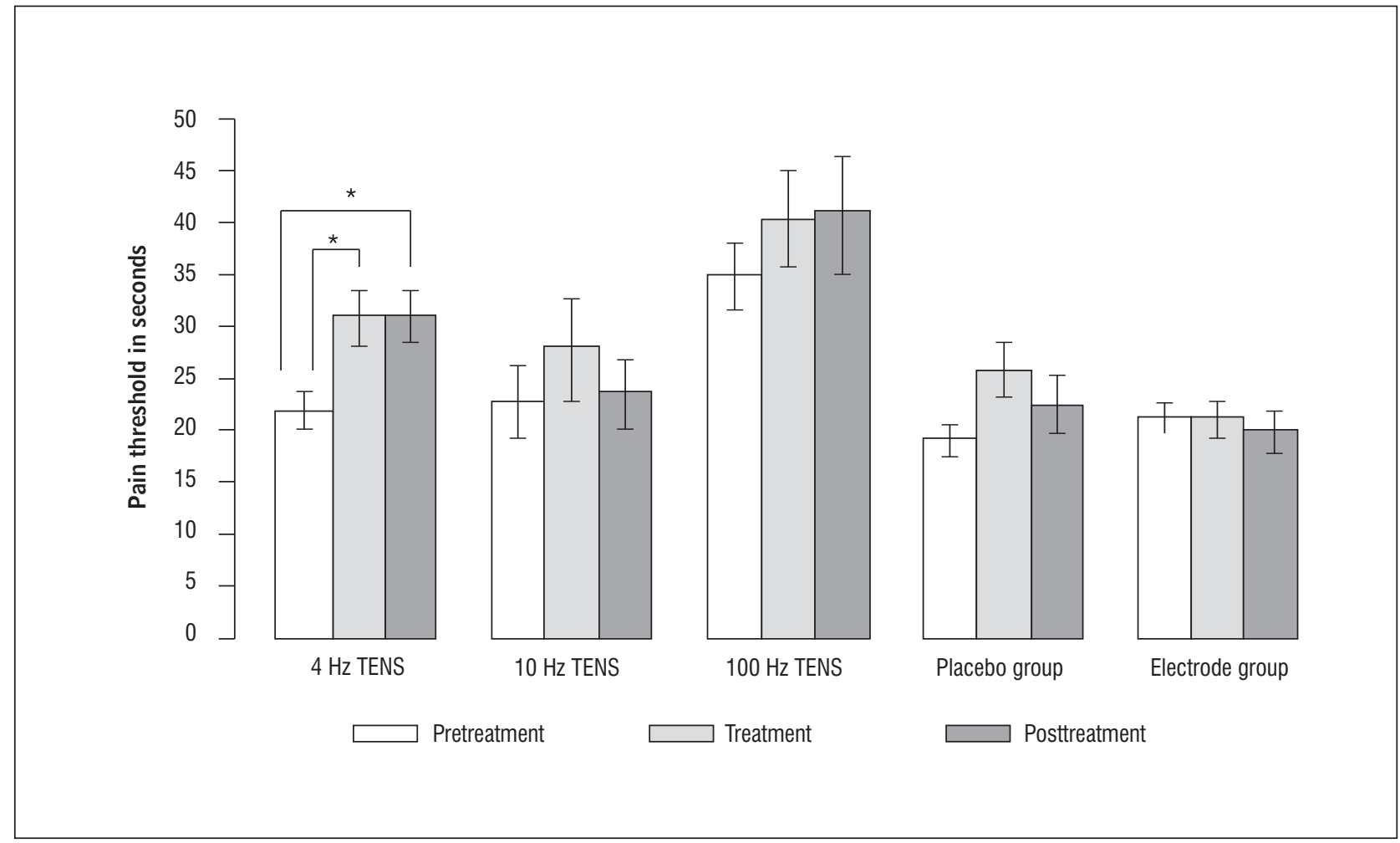

Figure 3 - The arithmetic mean of the pain threshold in seconds for the five groups of subjects in the three experimental steps Note: The vertical lines in each bar represent the standard error of the mean and the asterisk $\left(^{\star}\right)$ denotes $p$-value $<0.05$. A significant increase in pain threshold of $4 \mathrm{~Hz}$ TENS group from the first to the second stage occurred, this increase remained until the third stage, while in the other groups there was no significant change between any of the steps.

In this case, the painful stimulus was triggered by a hypothermic stimulus, which activated the action potential in C- and A-delta nociceptive fibers through the opening of Nav1.8 channels (sodium voltage 1.8) and closing of $\mathrm{K}^{+}$(potassium) channels, among others (30). The mechanism of pain caused by hypothermia is still not well understood. However, there is some evidence it is due to different types and families of ion channels $(31,32)$.

The postulations for the analgesia provided by low and high-frequency TENS are based on different mechanisms. Low-frequency electrical stimulation $(\leq$ $10 \mathrm{~Hz}$ ) evokes action potential in polymodal C- and A-delta nociceptive fibers. When this information reaches the segmental and suprasehmental centers, met-enkephalin and $\beta$-endorphin are released, activating opioid receptors. Conversely, the action potentials generated by high-frequency TENS $(\geq 50 \mathrm{~Hz})$ are sent to the segmental and suprasegmental centers through A-beta fibers. The response to this stimulus is serotonin release both in the brain and the spinal cord, and dynorphin and GABA (gamma-animobutyric acid) release in the spinal cord. The noradrenergic and cholinergic systems are also activated by TENS. Therefore, both low and high-frequency TENS have segmental and suprassegmental actions (33).

In this study, TENS was directly applied at the acupoint P7. We found an increased pain threshold latency in the $4 \mathrm{~Hz}$ TENS group. Based on what has been previously discussed above, we can surmise that the low-frequency stimulus and the high intensity stimulated fibers of smaller diameter (A-delta and C-fibers). This electrical stimulus may have triggered the diffuse noxious inhibitory control (DNIC), promoting analgesia by the noxious stimulus of the electric current versus the stimulus of the cold water. A significant effect was found during the treatment period and maintained even after the electrical stimulus had been turned off, probably due to the release of antinociceptive endogenous substances. Currently, acupoints are seen by Western science as a histological complex consisting of tiny capillaries, lymphatic vessels, and nerve fibers that, together, provide support to the tissue. They may respond to 
different physical parameters, such as the intensity and frequency of the physical component (34).

In the $100 \mathrm{~Hz}$ TENS group, we observed a behavior that was similar to the previous group, but the results were not significant. In this group, both the frequency and the current intensity differed. As stated previously, a high frequency with sensory intensities acts through the A-beta fibers, which would cause a significant effect during application through the release of GABA and dynorphin in the segmental region, and the release of serotonin in the suprasegmental region. Despite this known fact, due to other experiments (33), our results were not significant for increasing the pain threshold.

A critical point between the two groups that were paired-analyzed is the difference between the pain threshold values in the pretreatment cycles. In the $100 \mathrm{~Hz}$ TENS group, we found higher values (pain threshold latency) when compared to the $4 \mathrm{~Hz}$ TENS group. This variability is natural, as found by other authors (28). It demonstrates that the pain threshold may vary dramatically among subjects. This fact made it impossible to compare the groups.

We found that the Electrode group showed values that were very different from the aforementioned groups, but yielded a high internal consistency, with little changes among subjects with regard to the cycles. This corroborates the variability among subjects (experimental groups). The Electrode group was designed to minimize the confounding effect that could occur due to the presence of two physical phenomena acting on the acupoint: the mechanical (electrode) and the electrical (electric current). The data demonstrate that the mere placement of the electrodes does not bring about an effect on the behavior of the pain threshold.

The analysis of the $10 \mathrm{~Hz}$ TENS group shows no significant result. However, the analysis of the behavior of this group showed that it is different from the other two TENS groups, and similar to the Placebo group.

We have used the same experimental model in a previous study (25), and found significant results regarding an increased pain threshold in the posttreatment phase, when compared to the pretreatment phase, using $10 \mathrm{~Hz}$ TENS on TE5 and PC6 acupoints. This result differs from the one found in this study. The TE5 and PC6 acupoints were stimulated with electrodes which had an area of $15 \mathrm{~cm}^{2}$ while the LU7 acupoint was stimulated with electrodes which had an area of $1 \mathrm{~cm}^{2}$. Larger electrodes stimulate acupoints as well as adjacent areas (dermatomes). This increases the likelihood of interference with the analyzed features, since a larger number of nerve endings are stimulated. Thus, we confirmed that not only different acupoints but also the size of the electrodes may bring different results.

Chesterton et al. (35), using a pressure-induced pain model, obtained an increase in analgesia in the treatment cycle by stimulating the LU7 and SI6 acupoints with $110 \mathrm{~Hz}$ TENS. This effect, however, did not persist in the post-stimulation period. This fact was not observed in the $100 \mathrm{~Hz}$ TENS group in our study. Nevertheless, the stimuli in the study by Chesterton et al. (35) were applied to more acupoints and a different pain model was used.

Wang and Hui (23) observed an increase in the pain threshold after application of $100 \mathrm{~Hz}$ TENS at the SI4 acupoint and using a heat-induced pain model in healthy volunteers. This result differs from the ones previously cited, because its effectiveness occurred after the stimulus, mimicking the effect of low frequency. Other than the fact that the acupoints are different, what is most striking is that different pain models were applied in the experiments.

Corroborating this assertion, Chesterton et al. (35) used a pressure-induced pain model and applied $4 \mathrm{~Hz}$ TENS (strong intensity) to LU7 and SI6 acupoints, in order to identify its influence on the pain threshold. They found that it had no effect on the analyzed variable.

In the placebo group, we observed an interesting behavior: the numeric increase of the pain threshold in the treatment cycle, during which the subjects of this group were led to believe that a microcurrent was being delivered. Despite this numerical increase, there was no statistical difference. In the post-treatment period, during which the supposed microcurrent is no longer being delivered, values fall in relation to the previous period. This was only observed in the $10 \mathrm{~Hz}$ TENS group. Thus, we do not know whether the internal behavior of the $10 \mathrm{~Hz}$ TENS group was promoted by the real effect of the electric current or was simply a non-verbally induced placebo effect, which occurred due to the sensation of electric current. This group showed a distinct behavior from the Electrode group (which was more internally balanced) and the $4 \mathrm{~Hz}$ and $100 \mathrm{~Hz}$ TENS groups.

Although the result is not significant in the 10 $\mathrm{Hz}$ and $100 \mathrm{~Hz}$ TENS groups and in the Placebo 
group, their internal behavior was different from the Electrode group, which had no verbal or sensory influence. This may indicate an internal potential of these groups, which should be further investigated through an increase in the number of volunteers.

Some authors state that the placebo effect can mimic the action, duration and side effects of the real therapy, even releasing chemicals responsible for the therapeutic effects (36). However, it is known that some individuals are more susceptible than others (37).

Therefore, we found that the pain models, the stimulated acupoint and the size of the electrodes used in the experiments are of fundamental importance in the choice of electrical stimulation parameters with analgesic purposes. Most probably, in each case of nociceptive transduction to the central nervous system, different molecular mechanisms are triggered by various noxious stimuli. Thus, specific anti-algic stimuli are needed for each case.

\section{Conclusion}

This study suggests that $4 \mathrm{~Hz}$ TENS applied to the LU7 acupoint and the immediately proximal meridian area using $1 \times 1 \mathrm{~cm}$ electrodes increases the coldinduced pain threshold in healthy young subjects and that this effect is maintained even after their removal. A potential clinical application is the use of this resource in patients who present with acute pain in the hands. However, further clinical studies need to be conducted in order to better adjust the stimulation parameters to different types of pain and physiological conditions.

\section{References}

1. Merskey H, Albe-Fessard DG, Bonic JJ. Pain terms: a list with definitions and notes on usage - recommended by the IASP Subcommittee on Taxonomy. Pain. 1979;6(3):249.

2. Rocha APC, Kraychete DC, Lemonica L, Carvalho LR, Barros GAM, Garcia JBS, et al. Dor: aspectos atuais da sensibilização periférica e central. Rev Bras Anestesiol. 2007; 57(1):94-105.
3. Langley PC, Tornero MJ, Margarit-Ferri C, PérezHernández C, Tejedor-Varillas A, Ruiz-Iban MA. The association of pain with labor force participation, absenteeism, and presenteeism in Spain. J Med Econ. 2011;14(6):835-45.

4. Whipple B. Methods of pain control: review of research and literature. J Nurs Scholarsh. 1987;19(3):142-6.

5. Odsberg A, Schill U, Haker E. Acupuncture treatment: side effects and complications reported by Swedish physiotherapists. Complement Ther Med. 2001;9(1):17-20.

6. Ernst E, Sherman KJ. Is acupuncture a risk factor for hepatitis? Systematic review of epidemiological studies. J Gastroenterol Hepatol. 2003;18(11):1231-6.

7. Ernst G, Strzyz H, Hagmeister H. Incidence of adverse effects during acupuncture therapy: a multicentre survey. Complement Ther Med. 2003;11(2):93-7.

8. Woo PC, Lau SK, Wong SS, Yuen KY. Staphylococcus aureus subcutaneous abscess complicating acupuncture: need for implementation of proper infection control guidelines. New Microbiol. 2003,26(2):169-74.

9. Patrick BS. Acupuncture complication: a case report. J Miss State Med Assoc. 2005;46(7):195-7.

10. Schikora D. Laserneedle acupuncture: a critical rewiew and recent results. Med Acupunct. 2008;20(1):37-42.

11. Zeredo JL, Sasaki KM, Toda K. High-intensity laser for acupuncture-like stimulation. Lasers Med Sci. 2007;22(1):37-41.

12. Colbert AP, Cleaver J, Brown AK, Harling N, Hwang Y, Shiffke HC, et al. Magents applied to acupuncture points as therapy: a literature rewiew. Acupunct Med. 2008;26(3):160-70.

13. Lee EJ, Frazier SK. The efficacy of acupressure for symptom management: a systematic review. J Pain Symptom Manage. 2011;42(4):589-603.

14. Ng MCS, Jones AYM, Cheng LC. The Role of AcuTENS in Hemodynamic Recovery after Open-Heart Surgery. Evid Based Complement Alternat Med. 2011;2011:301974.

15. Wang B, Tang J, White PF, Naruse R, Sloninsky A, Kariger R, et al. Effect of the intensity of transcutaneous acupoint electrical stimulation on the postoperative analgesic requirement. Anesth Analg. 1997; 85(2):406-13. 
16. Yuan CS, Attele AS, Dey L, Lynch JP, Guan X. Transcutaneous electrical acupoint stimulation potentiates analgesic effect of morphine. J Clin Pharmacol. 2002;42(8):899-903.

17. Han JS. Acupuncture analgesia: areas of consensus and controversy. Pain. 2011;152 (3 Suppl):S41-8.

18. Francis RP, Marchant P, Johnson MI. Conventional versus acupuncture-like transcutaneous electrical nerve stimulation on cold-induced pain in healthy human participants: effects during stimulation. Clin Physiol Funct Imaging. 2011;31(5):363-70.

19. Melzack R, Wall PD. Pain mechanisms: a new theory. Science. 1965;150(3699):971-9.

20. Li A, Wang Y, Xin J, Lao L, Ren K, Berman BM, et al. Electroacupuncture suppresses hyperalgesia and spinal Fos expression by activating the descending inhibitory system. Brain Res. 2007;1186:171-9.

21. Attele AS, Mehendale S, Guan X, Dey L, Yuan CS. Analgesic effects of different acupoint stimulation frequencies in humans. Am J Med Chin. 2003;31(1):157-62.

22. Gao M, He L. Increase of mu opioid receptor density in rat central nervous system following formalin nociception and its enhancement by electroacupuncture. Sheng Li Xue Bao. 1996;48(2):125-31.

23. Wang N, Hui-Chan, C. Effects of acupoints TENS on heat pain threshold in normal subjects. Chin Med J. 2003;116(12):1864-8.

24. Chesterton LS, Barlas P, Foster NE, Lundeberg T, Wright CC, Baxter GD. Sensory stimulation (TENS): effects of parameter manipulation on mechanical pain thresholds in healthy human subjects. Pain. 2002; 99(1-2):253-62.

25. Montenegro EJN, Albuquerque NB, Mariz LMR, Costa RCS, Montarroyos CS, Motta, MA. Ação da TENS acupuntural em acupontos na dor induzida pela hipotermia local (0-2 $\left.{ }^{\circ} \mathrm{C}\right)$. Fisioter Mov. 2010;23(3):483-92.

26. Johnson MI, Tabasam G. An investigation into the analgesic effects of different frequencies of the amplitudemodulated wave of interferential current therapy on cold-induced pain in normal subjects. Arch Phys Med Rehabil. 2003;84(9):1387-94.

27. Stux G, Pomerang B. Bases da acupuntura. 4⿳亠丷a ed. São Paulo: Editorial Premier; 2004.
28. Johnson MI, Tabasam G. A double blind placebo controlled investigation into the analgesic effects of inferential currents (IFC) and transcutaneous electrical nerve stimulation (TENS) on cold-induced pain in healthy subjects. Physiother Theory Pract. 1999;15(4):217-33.

29. Tulgar M, Tulgar O, Herken H. Psychophysical responses to experimentally induced heat and cold pain before, during, and after transcutaneous electrical nerve stimulation. Neuromodulation. 2003;6(4):229-36.

30. Zimmermann K, Leffler A, Babes A, Cendan CM, Carr RW, Kobayashi J, et al. Sensory neuron sodium channel Nav1.8 is essential for pain at low temperatures. Nature. 2007;447(7146):855-8.

31. Viana F, de la Peña E, Belmonte C. Specifity of cold thermotransduction is determined by differential ionic channel expression. Nat Neurosci. 2002;5(3):254-60.

32. McKemy DD, Neuhausser WM, Julius D. Identification of a cold receptor reveals a general role for TRP channels in thermosensation. Nature. 2002;416(6876):52-8.

33. Sluka KA, Walsh D. Transcutaneous electrical nerve stimulation: basic science mechanisms and clinical effectiveness. J Pain. 2003,4(3):109-21.

34. Niemtzow RC. Acupuncture point electrical surface charges and transmembrane potentials involved in cell signalization. Med Acupunct. 2007;19(3):123-4.

35. Chesterton LS, Foster NE, Wright CC, Baxter GD, Barlas P. Effects of TENS frequency, intensity and stimulation site parameter manipulation on pressure pain thresholds in healthy human subjects. Pain. 2003;106(1-2):73-80.

36. Holden C. Drugs and Placebos Look Alike in the Brain. Science. 2002;295:0947.

37. Johnson MI, Din A. Ethnocultural differences in the analgesic effects of placebo transcutaneous electrical nerve stimulation on cold-induced pain in healthy subjects: a preliminary study. Complement Ther Med. 1997;5:74-9.

Received: 02/13/2014

Recebido: 13/02/2014

Approved: 08/20/2014

Aprovado: 20/08/2014 